\title{
“COMO NÃO ADIANTAR O FIM DO MUNDO": EDUCAÇ̃̃O EM TEMPOS DE PANDEMIA
}

\author{
“COMO NÃO ADIANTAR O FIM DO MUNDO”: EDUCATION IN PANDEMIC
}

PERIOD

\section{Samira dos Santos Ramos ${ }^{1}$}

Fabiana Pomin ${ }^{2}$

Lilian Machado Marques Vidal ${ }^{3}$

Willians Ribeiro Mendes ${ }^{4}$

Recebido: 29/12/2020

Aceito: $31 / 12 / 2020$

Resumo: O projeto integrador Como não adiantar o fim do mundo propôs ações interdisciplinares durante a implementação do Regime de Exercício Domiciliar no IFMT, Campus Primavera do Leste (PDL), em resposta à crise provocada pela Pandemia da Covid19 no ano de 2020. Para tanto, os docentes de distintas disciplinas presentes no currículo dos cursos de Ensino Médio Integrado ao Técnico propuseram como temática o estudo das relações homem-natureza com intenção de possibilitar o diálogo sobre a importância do conhecimento científico de todas as áreas do conhecimento para prolongar a vida humana em nosso planeta através da compreensão da complexidade das representações do ser humano como indivíduo, ser social e ser natural; da finitude dos recursos naturais e da importância do desenvolvimento científico na resolução de problemas de forma ética. Este relato de experiência tem como objetivo refletir sobre a práxis, bem como os limites sucessos do projeto, comparando-os com a análise das respostas dos alunos sobre a satisfação quanto à participação do projeto e suas impressões finais, coletadas através de um formulário composto por duas questões em escala Likert e um campo para comentários. Considera-se que apesar dos limites impostos pelo ensino remoto, o projeto teve avaliação majoritariamente positiva entre os estudantes nas questões de escala de avaliação. Nos comentários foi possível documentar as principais dificuldades e mapear parte das avaliações negativas. Como resultado parcial, observou-se que os principais desafios estiveram ligados

\footnotetext{
${ }^{1}$ Mestra em Letras pela Universidade de São Paulo (USP). Professora na Instituto Federal de Mato Grosso (IFMT). E-mail: samira.ramos@pdl.ifmt.edu.br

2 Doutora em Ciências da Atividade Física e do Esporte (UDC/ES). Professora na Instituto Federal de Mato Grosso (IFMT). E-mail: fabiana.pomin@pdl.ifmt.edu.br

3 Mestra em Ciências Ambientais pela Universidade do Estado de Mato Grosso (UNEMAT). Professora na Instituto Federal de Mato Grosso (IFMT). E-mail: lilian.marques@pdl.ifmt.edu.br 4 Doutor em Engenharia Elétrica pela Universidade Federal do Rio Grande do Norte (UFRN). Professor no Instituto Federal de Educação, Ciência e Tecnologia de Mato Grosso (IFMT). E-mail: willians.mendes@pdl.ifmt.edu.br
} 
às representações tradicionais de ensino, avaliação e conteúdo, ao gerenciamento do tempo e a falta de experiência dos estudantes com as metodologias interdisciplinares.

Palavras-chave: Interdisciplinaridade; metodologia baseado em projetos; ensino remoto; educação profissional.

Abstract: The integrative project How to avoid the end of the world proposed interdisciplinary actions during the implementation of the Home Exercise Regime at the IFMT, Campus Primavera do Leste (PDL), in response to the crisis caused by the Covid-19 Pandemic in 2020. Teachers from different disciplines present in the curricula of the Integrated and Technical High School courses proposed as a theme to study of man-nature relations in order to enable a dialogue on the importance of scientific knowledge from all areas of knowledge for the extension of human life on our planet to media to understand the complexity of the representations of the human being as an individual, social being and natural being; the finitude of natural resources and the importance of scientific development in the ethical solution of problems. This experience aims to reflect on the praxis, as well as the limits of the project's successes, comparing them with the analysis of the students' responses on the satisfaction with the participation in the project and their final impressions, collected through a form composed of two questions on the Likert scale and field for comments. It is considered that despite the limits imposed by distance education, the project had a mostly positive evaluation of students on the questions of the evaluation scale. In the comments, it was possible to document the main difficulties and map part of the negative evaluations. As a the result, it was observed that the main challenges were linked to traditional representations of teaching, assessment and content, time management, and the lack of experience of students with interdisciplinary methodologies..

Keywords: Interdisciplinarity; project-based methodology; remote teaching; professional education.

\section{Introdução}

No início de 2020 chegou ao Brasil a maior crise humanitária do século XXI, a pandemia da Covid-19, que além de acarretar incomensurável perda de vidas, expôs as fragilidades do poder e do serviço públicos em lidar com a emergência. Em nosso entendimento, a educação brasileira deparou-se com três dimensões de desafios e limites. A primeira, estrutural, explicitou a incapacidade dos sistemas públicos de ensino de garantir estratégias que atendessem a todos os estudantes, acentuando as desigualdades de acesso ao conhecimento conforme as persistentes desigualdades sociais ocasionadas pela precarização de relações trabalhistas, da insuficiência das políticas habitacionais e da escassez de saneamento básico. A segunda, de ingerência governamental e ausência de diálogo com sistemas de ensino, bem como com as entidades estudantis que cobravam esclarecimento sobre o adiamento das datas das avaliações nacionais, gerando insegurança jurídica para as 
instituições e insatisfação dos estudantes. Por fim, o ataque simbólico ao próprio conhecimento, através do descrédito às universidades, diminuição de recursos e da negação à ciência.

Em meio a este panorama, nós, alguns professores do Instituto Federal de Mato Grosso (IFMT), campus Primavera do Leste, chegamos à compreensão que o interesse por novas estratégias de ensino que era movimento individual em nossa prática somava-se com a compreensão de que a educação necessitava aprofundar novas posturas em suas relações com a sociedade. Assim, mediante à crise, reunimo-nos em grupo para lidar com o desafio de

discutir os impactos dessa crise na forma como as sociedades lidam e se relacionam com a natureza, com a economia e com o conhecimento acerca das mais variadas dimensões do conhecimento que embasam o entendimento do momento atual para que, a partir dessa compreensão, fosse possível encontrar saídas para este cenário, (RAMOS et al, 2020, p. $06)$.

O interesse fundamental era combater o utilitarismo da visão neoliberal através da reafirmação do espaço escolar como um lugar de compreensão, contextualização e reflexão sobre o mundo e sobre si. Impingir ao ensino em meio à pandemia da Covid-19 o entendimento de que é através da produção científica e tecnológica, apoiadas na ética solidária e na visão holística do planeta que poderíamos não adiantar o fim do mundo, ou seja, responder às ameaças à vida humana na Terra.

Para os docentes articuladores do projeto, toda a educação brasileira foi compelida a discutir "como a escola vai inserir os contextos da crise sanitária em seus currículos e quais serão as transformações e adaptações necessárias para que a educação no século XXI possa responder de forma mais efetiva às necessidades da sociedade para este novo século" (RAMOS et al., 2020, p. 06).

Assim, o projeto Como não adiantar o fim do mundo foi organizado de forma a privilegiar as atividades multidisciplinares ${ }^{5}$ e interdisciplinares ${ }^{6}$, usando a própria crise

\footnotetext{
5 "A multidisciplinaridade ocorre quando determinado fenômeno a ser analisado solicita aporte de vários especialistas de diferentes disciplinas para explica-lo, ou para tentar resolver um problema”. (ARAÚJO, 2014, $\mathrm{s} / \mathrm{p})$.

${ }^{6}$ Transdisciplinar: “(...) temáticas que ultrapassam a própria articulação entre as disciplinas”. (ARAÚJO, 2014, $\mathrm{s} / \mathrm{p})$
} 
sanitária causada pela pandemia como um dos eixos norteadores para a construção de um diálogo entre diferentes áreas de conhecimento.

A hipótese dos docentes era de que seria fundamental uma reflexão sobre a necessidade de transição para educação interdisciplinar e transdisciplinar mais integrada e conectada com temas atuais, que proporcionasse aos participantes do processo de ensino e aprendizagem experiências menos fragmentadas de pensar o mundo.

\section{Educação em tempos de pandemia: entre medos, expectativas, discursos e práticas}

De acordo com o documento Projeto de Ensino Integrador Como não adiantar o fim do mundo (RAMOS et al, 2020, p. 05), inicialmente considerávamos que a adaptação da educação em resposta à crise seria imediata e inevitável:

vivemos em um mundo em constante transformação, onde o acesso ampliado às mídias digitais, internet e tecnologias coloca-nos desafios para disponibilizá-las democraticamente à comunidade escolar. Apesar da possibilidade de canais de comunicação e trabalho integrado e colaborativo, o tradicionalismo disciplinar muitas vezes limita a integração entre as diversas áreas do conhecimento. A pandemia da Covid-19 revelou que a educação pública no Brasil precisava se adaptar em resposta à crise, enquanto os benefícios deste processo poderiam se configurar na efetivação permanente de uma transição para uma práxis do ensino interdisciplinar que superasse as barreiras da disciplinaridade.

Em contato com a transdisciplinaridade, os professores buscaram integrar os aspectos legais do cumprimento de ementa e carga horária, inerentes ao ano letivo de acordo com os currículos dos cursos, com estudos sobre interdisciplinaridade e metodologia baseada em projetos, buscando as intersecções dos conhecimentos para integrar os estudos em época de pandemia, quando há ameaça à vida humana em curso. A expectativa era responder à pandemia da Covid-19 com a ação pedagógica que possibilitasse:

contextualizar, conhecer, pensar e agir sobre esta situação, afirmando que é justamente a educação o serviço essencial neste momento, pois é por meio da produção de conhecimento científico e tecnológico pautado na ética, nos direitos humanos e na compreensão holística da vida na terra que poderemos responder às ameaças à vida correntes e as que podem surgir, (RAMOS et al, 2020, p. 06)

Entretanto, de forma geral, a urgência das mudanças não alterou os paradigmas estabelecidos socialmente sobre o processo de ensino e aprendizagem. Pelo Brasil, as representações de professores, alunos, gestores e comunidade sobre aprendizagem, conteúdo 
e avaliação somaram-se à sobrecarga de trabalho gerada pela necessidade de adaptar conteúdos para novas mídias, monitorar individualmente o trabalho dos alunos e atender às especificidades de aprendizagem em um momento de rompimento com a rotina ordinária escolar, gerando a sensação de insucesso e frustração nos atores do processo educativo, traduzida, por muitos, na sensação de "ano perdido". Assim, a transição para a práxis interdisciplinar, longe de se constituir como um movimento orgânico de resposta à crise, permaneceu como esforços pedagógicos isolados de transgressão às lógicas da disciplinaridade constantes em nosso sistema educacional.

No campus Primavera do Leste não foi diferente, o projeto integrador dividiu espaço com as disciplinas regulares de cada curso. No momento inicial da suspensão das aulas presenciais, seis professores de cinco áreas trabalharam exclusivamente pelo projeto integrador, enquanto os outros onze revezaram entre os conteúdos disciplinares e o projeto. Conforme se estendeu a suspensão de aulas, foi necessário que todos os professores trabalhassem os conteúdos não abrangidos pelo projeto de forma disciplinar, concomitantemente com as atividades interdisciplinares.

\section{3 “Como não adiantar o fim do mundo": algumas considerações estruturais e teóricas do projeto}

A equipe do projeto foi constituída por onze professores de oito de áreas do conhecimento, conforme a tabela abaixo:

Tabela 1 - áreas do conhecimento e professores

\begin{tabular}{|l|l|}
\hline $\begin{array}{l}\text { Áreas do Conhecimento / } \\
\text { disciplinas }\end{array}$ & Professores responsáveis \\
\hline Administração & Prof. Me. Augusto Paschoalino \\
\hline Biologia & $\begin{array}{l}\text { Prof. Me. Alexandre Fagundes Cesário } \\
\text { Prof. Dr. Denis Silva Nogueira } \\
\text { Prof. Ma. Lilian Machado Marques Vidal }\end{array}$ \\
\hline Educação Física & Prof. Dra. Fabiana Pomin \\
\hline Engenharia Elétrica & Prof. Dr. Willians Ribeiro Mendes \\
\hline Geografia & $\begin{array}{l}\text { Prof. Dr. Renato Emanuel da Silva } \\
\text { Prof. Me. Frank Chagas }\end{array}$ \\
\hline
\end{tabular}




\begin{tabular}{|l|l|}
\hline $\begin{array}{l}\text { Língua Estrangeira Moderna } \\
\text { (Inglês) / Língua Portuguesa e } \\
\text { Literatura }\end{array}$ & Prof. Me. Hugo Giazzi Senhorini \\
\hline Língua Portuguesa e Literatura & Prof. Ma. Samira dos Santos Ramos \\
\hline Química & Prof. Dr. Francisco Xavier \\
\hline
\end{tabular}

Nota-se que havia representantes das áreas de ciências da natureza, ciências sociais, linguagens e duas áreas do ensino técnico. A única área do conhecimento do currículo básico não integrada diretamente ao projeto foi matemática. Além dos professores listados, outros professores, alunos extensionistas e técnicos do campus Primavera do Leste colaboraram elaborando aulas e participando de eventos em momentos pontuais.

O público do projeto foi constituído de alunos do Ensino Médio Integrado ao Técnico em quatro cursos: Informática, Logística, Eletrotécnica e Eletromecânica. Ao todo, o projeto foi oferecido para as 21 turmas de $1^{\circ} \mathrm{s}, 2^{\circ} \mathrm{s}$ e $3^{\circ} \mathrm{s}$ anos, com um total de 638 alunos inscritos (PAGANI, 2020). Dos 638 alunos matriculados e participantes do projeto, 30 $(4,7 \%)$ não acessou, 4 informaram não dispor de internet, e 2 realizaram as atividades com material impresso.

Esta primeira diferenciação entre projeto integrador e os projetos de ensino causou estranhamento entre os alunos, visto que o primeiro é uma metodologia com estratégias de ensino escolhidas pelos professores titulares das turmas, não sendo optativo. O segundo, por sua vez, ocorre ocasionalmente no campus e é paralelo às disciplinas e não obrigatório. Assim, inicialmente diversos alunos, apesar de comunicados pelos professores, não realizaram as atividades do projeto ou não as realizaram com a mesma prioridade que as atividades disciplinares.

O projeto foi inicialmente organizado em duas fases. A primeira, multidisciplinar, na qual cada professor desenvolveria um conteúdo introdutório sobre como a sua disciplina ou área de conhecimento contribuiria para pensar o eixo temático. A segunda, interdisciplinar, usando a metodologia baseada em projetos, buscaria resolver e responder as questões levantadas pelos alunos na primeira fase. Por fim, a culminância aconteceria através de trabalhos teóricos, protótipos, portfólios, materiais didáticos, de acordo com as perguntas e problemas respondidos. 
No entanto, em primeiro contato com os estudantes, percebeu-se a necessidade de inserir um módulo introdutório, com intenção de habituar os adolescentes ao ensino remoto e também receber as ansiedades, temores e questionamentos de pessoas que passaram aproximadamente quarenta dias com aulas suspensas e poucas informações se voltariam as aulas, como e quando isso aconteceria, e quais seriam os impactos disso em suas formações acadêmicas e nas avaliações nacionais, como o Exame Nacional do Ensino Médio (ENEM). Além disso, refletir juntamente com os alunos sobre os diferentes conflitos sociais, econômicos, emocionais que a pandemia acarretou.

Assim, o projeto iniciou com o Módulo Introdução, no qual tratamos da ferramenta de avaliação, o Diário de Bordo e de abordagens filosóficas, psicológicas e biológicas do conceito de vida e das ameaças a ela, bem como as tecnologias de inteligência artificial criadas para solucionar essas ameaças.

Em seguida, a primeira fase do projeto foi organizada em três eixos: Eixo I Cuidado, frágil - o ambiente ameaça o homem: que abrangeu pandemias, estudos sobre as relações entre a peste negra, a gripe espanhola e a Covid-19; Hipótese de Gaia, com as relações entre os fenômenos naturais e as alterações ambientais; e Asteroides, discutindo as possibilidades de impacto com a terra e as tecnologias que podem evitar este fenômeno. Eixo II - Do princípio ao precipício - o homem ameaça o ambiente: eixo que discutiu a ação antrópica e todas as suas relações, abrangendo da formação da cultura à sociedade póscontemporânea ocidental e suas relações com o ambiente através dos temas Administração, Sustentabilidade, Cultura, Soberania e Segurança Alimentar. Neste módulo inserimos também as atividades do Mexa-se, proposta de ensino de atividades físicas a serem realizadas individualmente ou com a família. Eixo III - “O homem é o lobo do homem”, que discutiria as principais ameaças do homem à vida humana, com os temas Fake News, Deepfake e Racismo.

As atividades eram disponibilizadas semanalmente pela plataforma Google Sala de Aula, serviço parte do G Suite for Education da empresa estadunidense Google LLC. Consistiam em videoaulas, links, textos, vídeos e formulários desenvolvidos ou selecionados pelos docentes envolvidos no projeto, através de pesquisas conjuntas e colaborativas, sobre os temas determinados. Os alunos, após acessarem os materiais, registravam em seu "Diário 
de Bordo"7 relatos de experiência acadêmicas ou pessoais sobre os temas, relatórios, dissertações ou outros gêneros textuais, conforme as orientações da semana. Este material era usado para a avaliação individual de cada aluno, observando sua compreensão sobre o tema, as relações que estabelecia entre os textos do projeto e com textos de outros segmentos, conhecimentos adquiridos no âmbito escolar e fora dele, como músicas, livros e filmes.

A culminância do projeto foi distribuída em quatro eventos: "I Seminário para Educação das Relações Étnico-Raciais"; "II Mostra de Biologia", com apresentação de trabalhos dos alunos; "Festival do Minuto: Como não adiantar o fim do mundo"; e "Encontro de Mentira: festival do minuto"; no qual grupos de alunos enviavam vídeos de até um minuto sobre os assuntos abordados no projeto. Havia também a possibilidade de enviar o relatório de um dos eventos como trabalho final, forma de participação solicitada pelos próprios alunos.

\section{0 projeto: avaliação do estudante}

Ao finalizar o último módulo e antes dos eventos de culminância, os alunos foram convidados a responder um formulário criado em 20 de outubro de 2020 e disponibilizado entre os dias 21 e 27 de outubro de 2020 por link no aplicativo Formulários Google, da G Suite for Education, e ao todo foram coletadas 346 respostas neste período.

O formulário foi dividido em duas seções. A primeira, composta com duas perguntas de múltipla escolha, uma que caracterizava o sujeito respondente, pedia que o estudante indicasse em qual ano do curso estava. A outra pedia que indicasse interesse por um dos eventos previamente apresentados. A seção encerrava com um campo para o estudante sugerir outras opções de trabalho final, caso nenhum dos eventos lhe interessasse.

A segunda sessão, que ora nos interessa, foi nomeada de "Avaliação sobre o projeto", e foi composta por três questões. Nas duas primeiras fizemos uso da escala Likert (adaptada), tipo de questionário que se constitui em uma escala intervalar que, utilizada para medida de opiniões e atitudes, essas posições medem proporções do mais desfavorável ao mais favorável (MARCONI e LAKATOS, 1996).

\footnotetext{
7 "O diário de bordo (ou caderno de campo) (...) em que são registradas as etapas realizadas ao longo do seu aprendizado. É preenchido ao longo de todo o trabalho e inclui anotações, rascunhos, fichamentos, entrevistas, imagens, fotografias, documentos, mapas conceituais, resultados, reflexões, descobertas e inclusive novas indagações" (POMIN, 202, s/p).
} 
A primeira questão "Sobre o seu interesse nos temas, nas metodologias e nas suas produções, você considera..." optamos por adaptar para quatro graus, retirando a possibilidade de o ponto intermediário representar a indecisão, pois a pergunta era pessoal e subjetiva, exigindo que o estudante examinasse seu grau de interesse. Assim, optou-se pela escala: Muito satisfatório; satisfatório; regular; e pouco satisfatório.

Os estudantes foram questionados por seu interesse em 5 pontos, conforme mostramos a seguir:

1) Temas abordados no projeto (Saúde mental, Mexa-se, Pandemias, Hipóteses para o fim do mundo, Racismo, Sustentabilidade, Inteligência Artificial, Fake News, Plágio, Soberania e Segurança alimentar...);

2) Metodologia das aulas (videoaulas, leitura, áudios, encontros virtuais etc);

3) Materiais disponibilizados (qualidade nos vídeos, textos, etc);

4) Produção do Diário de Bordo (avaliação qualitativa através da escrita),

5) Adequação tempo/atividades dentro do projeto.

Já na segunda pergunta, que pedia aos estudantes concordância com algumas afirmativas, optamos por apresentar 5 graus, conforme geralmente é feito, sendo um extremo o total desacordo (grau 1), e o outro extremo o total acordo (grau 5); o ponto intermediário (grau 3) representa o indeciso (ANASTASI, 1977). Porém, inserimos um grau de "não tenho opinião formada sobre isso", evitando a indução de respostas sem a devida reflexão. Assim, além do grau "não tenho opinião...", inserimos mais cinco graus: Concordo totalmente; Concordo; Indiferente (não concordo nem discordo); Discordo; Discordo totalmente. Deveriam apresentar o grau de concordância com doze afirmativas, que questionavam sobre os hábitos de estudo (afirmativas $1 ; 5 ; 10)$; sobre autoavaliações de aprendizagem $(3 ; 4 ; 8$; 11); avaliações dos docentes $(6 ; 7)$ e avaliação do projeto e sua metodologia $(2 ; 9 ; 12)$.

1) Eu teria aproveitado mais o projeto se fosse presencial.

2) O projeto contribuiu para eu conhecer temas importantes.

3) Eu escrevo com mais facilidade agora sobre os temas do projeto.

4) Eu tive facilidade em entender os materiais.

5) Eu me dediquei a fazer as atividades do projeto.

6) Os professores do projeto mostraram dedicação.

7) Os professores respondiam as minhas dúvidas.

8) Houve mudanças positivas em meus hábitos por causa do que aprendi no projeto. 
9) O projeto durante o ensino remoto facilitou meu aprendizado.

10) Tanto no projeto como fora dele, consegui me adaptar bem ao ensino remoto.

11) Eu aprendi de um jeito diferente no projeto.

12) Eu repetiria a experiência com outros temas.

Tanto as questões sobre o grau de interesse quanto as afirmativas correspondiam a pontos amplamente discutidos pelos professores nas reuniões periódicas de avaliação do projeto, interessando-nos dirimir as dúvidas sobre estes pontos com a visão dos alunos.

Por fim, visando ampliar o espaço para a avaliação, inserimos um campo opcional no qual os estudantes foram convidados a dizer algo mais que quisesse sobre o projeto.

\section{Análise dos dados}

Inicialmente, é fundamental dizer que nós, professores do projeto Como não adiantar o fim do mundo não esperávamos uma avaliação positiva, pois as reuniões remotas periódicas com os alunos nos indicavam que estes estavam cada vez mais ansiosos e esgotados conforme se aproximava o final do ano letivo. No entanto, fomos surpreendidos por avaliações extremamente reflexivas e satisfatórias. Apresentamos os dados aqui, considerando apenas o melhor e pior resultados, por necessidade de concisão (Tabela 2).

Tabela 2 - Dados as serem discutidos

\begin{tabular}{|c|c|}
\hline \multicolumn{2}{|l|}{ Primeira questão } \\
\hline $\begin{array}{l}\text { Sobre o seu interesse nos temas, nas metodologias e nas suas } \\
\text { produções, você considera que: }\end{array}$ & $\begin{array}{l}\text { Escala Likert } \\
\text { (adaptada) }\end{array}$ \\
\hline $\begin{array}{l}\text { Temas abordados no projeto (Saúde mental, Mexa-se, Pandemias, } \\
\text { Hipóteses para o fim do mundo, Racismo, Sustentabilidade, } \\
\text { Inteligência Artificial, Fake News, Plágio, Soberania e Segurança } \\
\text { alimentar...) }\end{array}$ & \multirow[t]{2}{*}{$\begin{array}{l}\text { Muito satisfatório } \\
\text { Satisfatório } \\
\text { Regular } \\
\text { Pouco satisfatório }\end{array}$} \\
\hline Adequação tempo/atividades dentro do projeto & \\
\hline \multicolumn{2}{|l|}{ Segunda questão } \\
\hline $\begin{array}{l}\text { Tanto no projeto como fora dele, consegui me adaptar bem ao ensino } \\
\text { remoto }\end{array}$ & \multirow{2}{*}{$\begin{array}{l}\text { Concordo tot. } \\
\text { Concordo } \\
\text { Indiferente }\end{array}$} \\
\hline & \\
\hline
\end{tabular}


Houve mudanças positivas em meus hábitos por causa do que aprendi no projeto.

Discordo

Discordo tot.

A primeira questão foi: "Sobre o seu interesse nos temas, nas metodologias e nas suas produções, você considera que os Temas abordados no Projeto foram: Muito satisfatório; satisfatório; regular; e pouco satisfatório (Figura 1).

Figura 1 - Interesse nos temas abordados no projeto.

Temas abordados no projeto (saúde mental, mexa-se, pandemias, hipóteses para o fim do mundo, racismo, sustentabilidade, inteligência artificial, fake news, plágio, soberania e segurança alimentar);

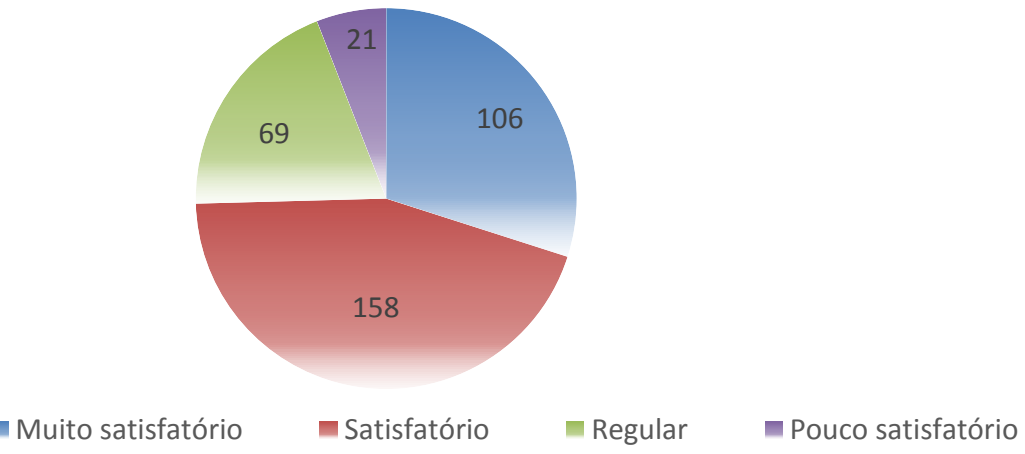

Para 74,5\% dos alunos que responderam os questionários acharam muito satisfatórios ou satisfatórios os temas abordados, o que demonstra o interesse despertado nos alunos pelos temas do projeto. Pode-se afirmar que os temas foram considerados interessantes pela maioria dos alunos, mostrando a assertividade da escolha dessas temáticas como condutoras do processo de aprendizagem.

Tal constatação vai em consonância com Zajac (2020), que considera apresentar aos alunos, por meio das tecnologias, temas relacionados ao seu dia-a-dia (como o caso da Covid-19 nesse período), torna-se um estímulo ao aprendizado, autonomia e protagonismo. Coloca ainda "Por que não usar essas ferramentas virtuais para se ensinar e conversar sobre as pandemias, sobre o valor e o sentido da vida, sobre as relações humanas, sobre sustentabilidade, saúde mental e papel da ciência?" (ZAJAC, 2020, s/p.).

A outra questão dentro do primeiro grupo de perguntas foi: "Sobre o seu interesse nos temas, nas metodologias e nas suas produções, você considera que a Adequação do tempo/atividades dentro do projeto foram: Muito satisfatório; satisfatório; regular; e pouco satisfatório (Figura 2). 
Figura 2 - Adequação tempo/atividades dentro do projeto

Adequação tempo/atividades dentro do projeto.

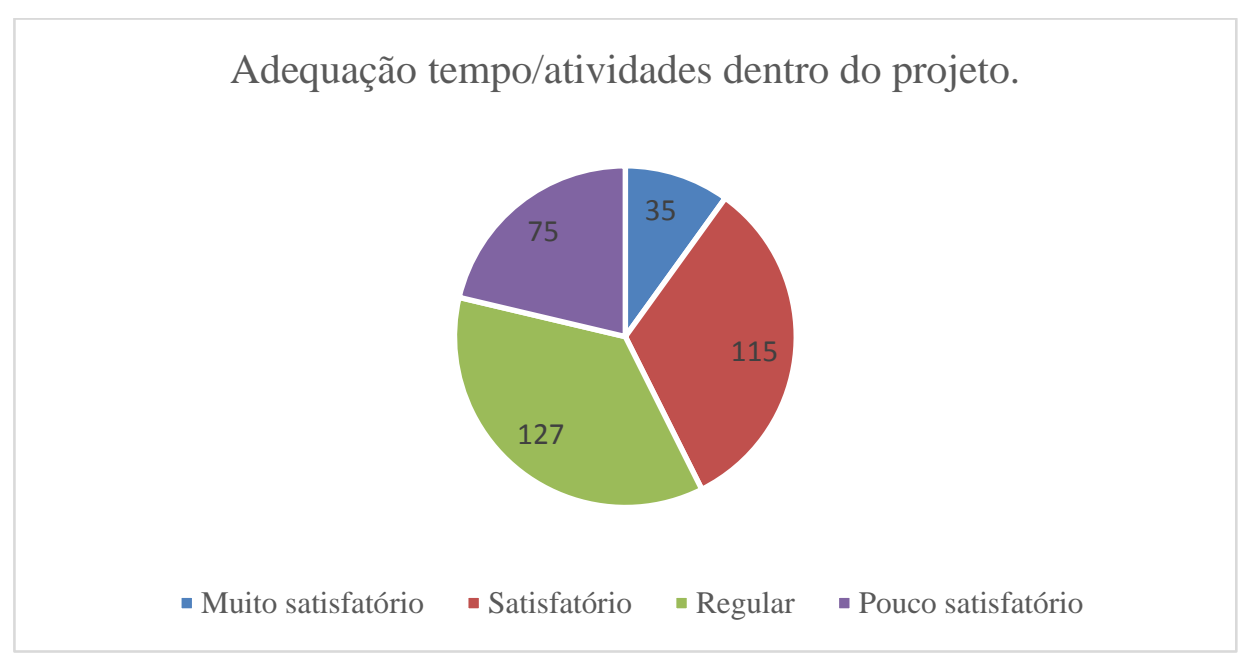

Por sua vez, a adequação entre o tempo e a quantidade de atividades teve a pior avaliação. Compreenderemos mais esta avaliação com a leitura dos comentários que os alunos apresentaram no campo opcional no qual foram convidados a dizer algo mais que quisesse sobre o projeto, os comentários estão ao final desse capítulo.

Sobre as questões de concordância com as afirmativas, selecionamos as duas que mais discutem os benefícios, desafios e limites do projeto em tempos de pandemia. Existe uma grande resistência do ser humano quando o assunto é mudança e quando se fala em mudar um método de ensino pode ser ainda mais complexo, pois demanda uma estrutura não presente na instituição e requer um esforço ainda maior para sua execução tanto por parte dos professores quanto dos estudantes. Pode se afirmar que a mudança vem ocorrendo de forma gradual, ao ver a Figura 3.

Figura 3 - Adaptação dos alunos ao ensino remoto

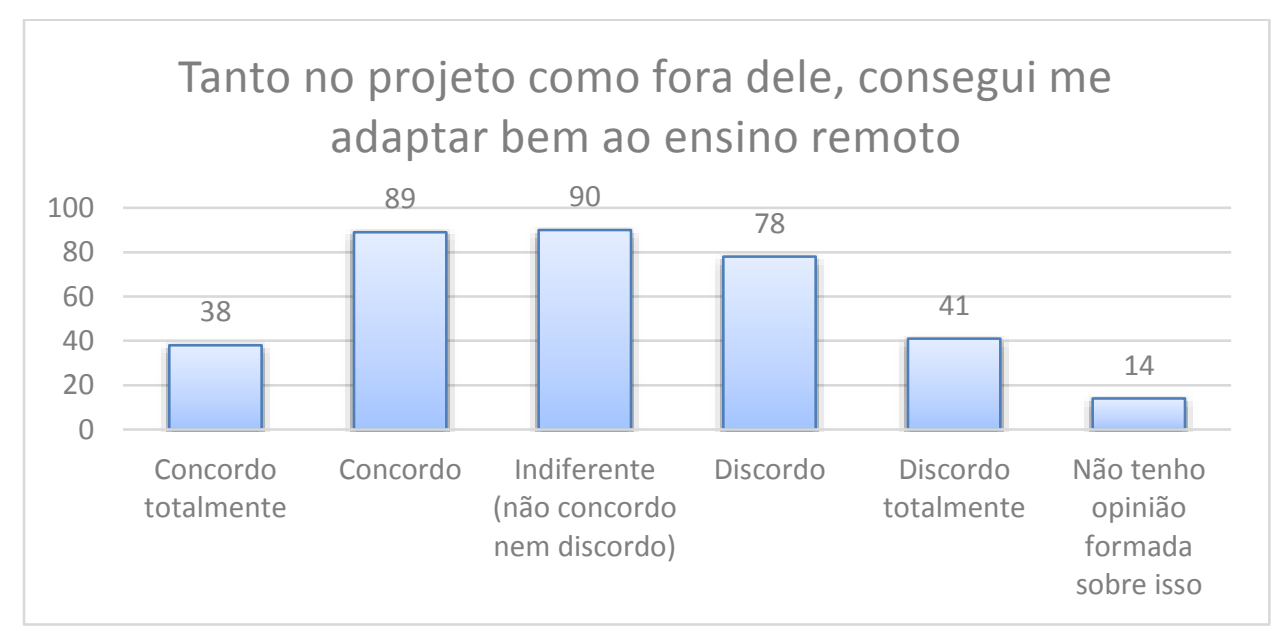


Pode-se estabelecer que $30 \%$ não tem opinião ou é indiferente ao assunto, entretanto $36 \%$ a maioria diz ter conseguido se adaptar ao ensino remoto, enquanto $34 \%$ dos alunos discordam terem conseguido se adaptar. O que confirma Prensky (2001), que coloca o avanço tecnológico como uma ação de mudança comportamental radical e com isso faz com que os alunos contemporâneos também mudem. Dessa forma os estudantes de hoje já não são os mesmos para os quais o sistema educacional foi criado.

Entre as dificuldades puderam ser observados fatores como: falta de estrutura (equipamentos, conexão à internet e plataformas digitais), letramento digital insuficiente, e a não oferta de formação aos professores sobre os recursos acadêmicos do ambiente virtual, observações estas, corroboradas por Alves (2020) e Silva et al. (2020). Médice, Tatto e Leão (2020), por sua vez, encontraram ainda relatos sobre a necessidade de interação com colegas e professores em um mesmo espaço físico, sobre a falta de um local adequado aos estudos no ambiente doméstico e sobre a dificuldade em estabelecer uma rotina de estudos.

A figura 4 apresenta a percepção dos alunos quanto a mudança de hábito após as discussões abordadas no projeto.

Figura 4 - Mudanças de hábitos

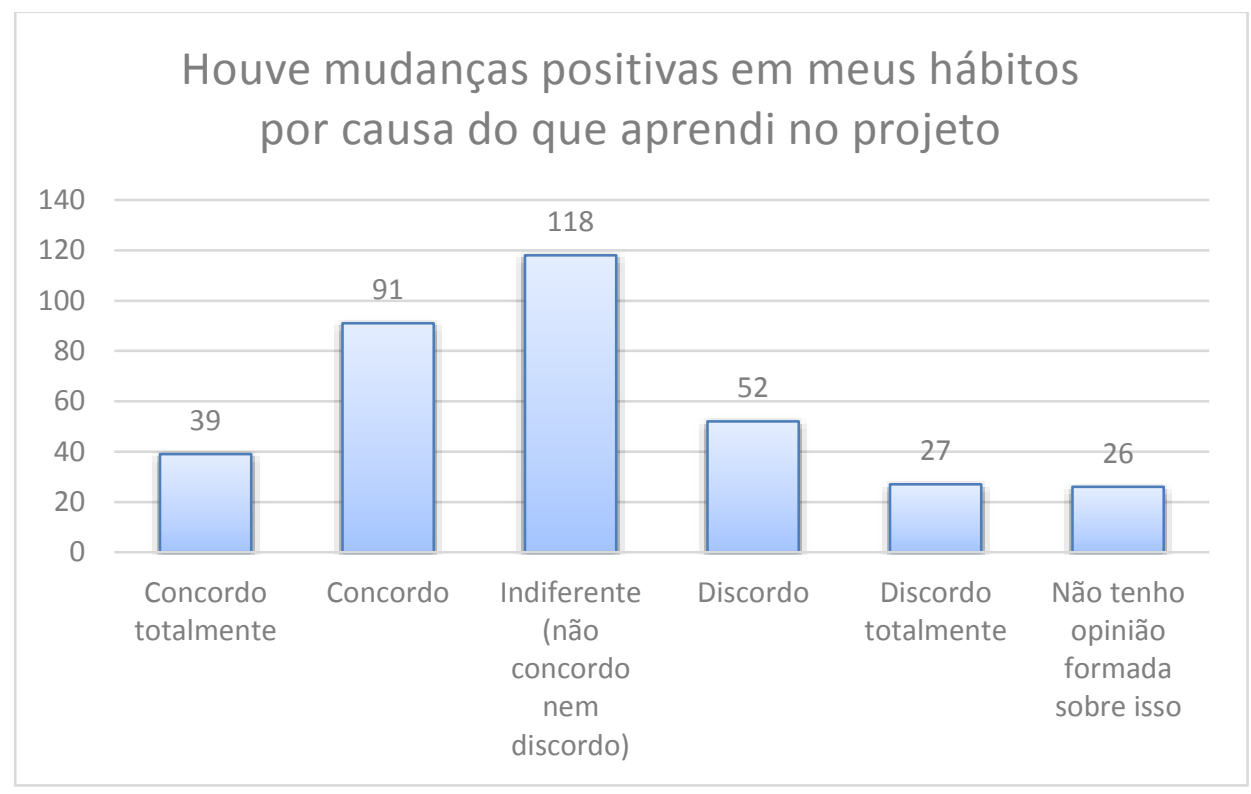

Em relação às mudanças de hábito, 130 alunos concordam que perceberam a influência do aprendizado do projeto, enquanto 79 discordam dessa afirmação. A questão foi provocada pelo relato de alguns alunos sobre melhor disposição para fazer atividades 
físicas, alteração de padrão de consumo e descarte de lixo, mudanças alimentares e assim por diante.

Assim, a metodologia de projetos descrita promoveu os objetivos do processo formativo, ou seja, produção de conhecimento e estímulo à transformação, por meio de uma ação sequencial, linear e com conexão de conteúdos, no qual os alunos puderem atuar como protagonistas, ampliando, mesmo que com certa resistência inicial, sua capacidade de ver, analisar e refletir sobre soluções aos problemas que a eles são apresentados por meio de suas disciplinas curriculares.

No espaço para comentários, que não era obrigatório, houve grande diversidade de opiniões sobre o projeto. Para identificação das falas, usaremos para a identificação dos sujeitos o número da linha na tabela, que foi automaticamente organizada conforme a ordem das respostas, e o ano a que pertence, único dado de identificação coletado, visando a maior liberdade de opinião.

Apresentamos aqui algumas das falas dos estudantes que ilustram principais ideias apresentadas pelos que colaboraram espontaneamente nesta parte da avaliação. Dividimos as avaliações em quatro categorias: 1) sobrecarga de atividades; 2) Considerações sobre a didática e metodologia; 3 ) Agradecimento e apoio; 4) Avaliação dos temas e sugestões. Aqui selecionamos três comentários de cada categoria, devido à necessidade de concisão.

1) sobrecarga de atividades:

"O projeto nos sobrecarregou muito, não foi uma experiência muito legal." (Sujeito $65,3^{\circ}$ ano).

"Olha teve semanas que foram muito sensacionais, mas teve umas que foram muito, muito cansativas. Mas vocês não têm culpa, porque não sabiam que outros professores postaram tantas tarefas ao mesmo tempo em algumas semanas. Todavia, eu amei aprender coisas novas e interessantes com vocês" (Sujeito $22,2^{\circ}$ ano).

"Eu repetiria a minha experiência se eu tivesse no presencial e tivesse mais tempo (pelo menos agora no final do ano, porque nos outros bimestres eu estava acompanhando, mas os professores estão passando muito conteúdo agora). Eu tive algumas dificuldades com o projeto, mas sempre que faço eu me dedico para fazer o melhor possivel, mesmo com atrasos ou sem o tempo necessário, pois estou tendo conteúdo do ensino médio e também estou estudando para o ENEM e vestibulares, o que faz meu tempo mais curto e as vezes não consigo ter muita disponibilidade nem muita vontade de fazer porque cansa muito." (Sujeito $319,3^{\circ}$ ano). 
Observa-se que a sobrecarga dos alunos esteve relacionada tanto à quantidade de materiais do projeto em algumas semanas quanto à concomitância com outras atividades acadêmicas e familiares. Ainda que a dedicação exigida ao projeto fosse de 4 horas semanais e os prazos fossem constantemente prorrogados, a quantidade de atividades de outras disciplinas, as demandas familiares e econômicas devido à pandemia e a própria dificuldade dos alunos em gerenciar o tempo foram desafios constantes.

Quanto à adequação das atividades do projeto ao tempo, o problema foi discutido constantemente pelos professores participantes e, apesar da sensação de esgotamento dos alunos, poucas vezes o tempo de dedicação ao material ultrapassou $2 \mathrm{~h}$ de atividade. Assim, compreendeu-se que a sensação de esgotamento dos estudantes não esteve relacionada ao tempo de dedicação às atividades, mas à qualidade do tempo e a concomitância com outras atividades.

Pôde-se ainda observar mais um fato que poderia ter colaborado com o sentimento de insuficiência de tempo para a realização das tarefas, tratando-se este do fato que maioritariamente os alunos realizam as tarefas apenas para a data de entrega, mesmo que geralmente os materiais motivadores fossem disponibilizados semanalmente. A postergação da realização das tarefas a serem entregues também foi constatada por Alves e Moreira (2017).

2) Considerações sobre a didática e metodologia:

"Gostaria que cada professor teria a sua sala de aula, tive muita dificuldade com isso (pelos professores não ter a sua própria sala). Acho que seria totalmente melhor." (Sujeito $50,1^{\circ}$ ano)

"Achei de extrema importância tratarmos sobre temas tão interessantes no decorrer desses meses, aonde estávamos muitas vezes exaustos psicologicamente, esse novo método de aprendizagem com questões que envolvem aprendizados para nosso dia-a-dia, não só acadêmico como também na formação de uma identidade. Quero parabenizar a todos os professores pela dedicação, que foi notável, pelo empenho, por compartilhar um pouco das experiências e hobbies de vocês, obrigada por ser um exemplo pra gente. Sentirei muita falta de todos vocês, que a vida possa nos reencontrar outras vezes." (Sujeito 146, $3^{\circ}$ ano).

"Uns professores se dedicaram as aulas mas na hora da conclusão das suas ideias colocaram vídeos e temas muito extensos e a atividade ficou enjoativa talvez o tema era legal mas ficou maçante, por pelo menos pra mim é horrivel ler matérias em uma tela de computador e muito mas cansativo que presencial, então uma dica seria ser mais simples e conciso mas atividades. E Parabéns a vocês pelo esforço pois está sendo muito difícil tanto 
pra gente (alunos) tanto pra vocês (professores), e não quero criticar ninguém por maldade é apenas uma crítica construtiva pra melhorar ambos os lados". (Sujeito 264; $2^{\circ}$ ano)

"Os temas não eram abordados de forma clara e sucintamente, começaram a ter muitos vídeos e muito longos, o que se tornava exaustivo e desinteressante, e quando questionados os professores eles diziam que nós conseguimos, mas não entendiam que tínhamos outras matérias." (Sujeito 242, $2^{\circ}$ ano).

\section{3) Avaliação dos temas e sugestões}

"Acredito que seria bom falar sobre cultura, povos e nos aprofundar sobre o que está a nossa volta tipo, conhecer muita mais a nossa história”. (Sujeito $105,1^{\circ}$ ano)

"Sobre a última opção; eu repetiria, MAS como eu queria ter MUITOS pontos de vista. Queria que o diálogo com o docente tivesse ficado mais próximo, mesmo que pelo ensino remoto. EU AMARIA TER TIDO MUUUUUITAS MAIS LIVES COM ESSAS CABEÇAS CHEIAS DE CONHECIMENTO QUE VOCÊS TÊM." (Sujeito 169, $2^{\circ}$ ano, [grifo do sujeito 169])

"Acho que o modo de avaliação deve ser levado em conta alguns pontos que os professores colocam, por exemplo, os professores precisam colocar o que eles vão avaliar a partir de tópicos e que esses tópicos estejam relacionados com um dos temas (como se fosse uma intertextualidade), ou que o que nó escrevemos sejam levados em conta para a nota, porque eu mesma, escrevi sobre um assunto, as partes que eu achava mais interessantes, e a nota que recebi não foi a que eu achei que eu merecia. Acho que quando forem fazer outros temas tentem colocar poucas coisas, por exemplo, ao invés de colocar 6 vídeos em um único tópico, coloque três em um dia e depois mais três em outro dia ou outro tópico, porque quando vemos a quantidade de coisas que temos que fazer desanima, ainda mais aqueles vídeos muito longos de explicação (não que a explicação dos professores seja ruim, mas seria bom se falassem um pouco mais rápido ou fizessem vídeos mais curtos) pelo menos nessa época." (Sujeito 319, $3^{\circ}$ ano).

\section{4) Agradecimento e apoio}

"Acredito que as negatividades sobre o projeto sejam uma questão pessoal de adaptação e organização, pois os temas abordados são tão atrativos quanto relevantes. Ademais, ter um espaço de debate e desenvolvimento mais aberto, como o projeto, dentro do ensino cria uma dinâmica mais produtiva e engajada. PS: Professores desculpem pelos 383883723812389162624981649461246986244861984664 atrasos." (Sujeito 102, $3^{\circ}$ ano)

"Obrigada a todos os professores que se dedicaram a este projeto, vcs são incríveis" (sujeito $80,3^{\circ}$ ano)

"Gostei bastante do Projeto! Foi como tinha imaginado e me auxiliou bastante na minha insegurança em relação a escrita." (sujeito $112,1^{\circ}$ ano)

De forma geral, mesmo ao tecerem as críticas mais contundentes, os estudantes agradeceram e reconheceram o esforço dos professores, entendendo que uma nova 
abordagem de ensino demanda inovação, pesquisa e trabalho, além de uma parceria fundamental entre docentes e discentes.

\section{Considerações Finais}

O presente trabalho mostrou alguns aspectos da aprendizagem baseada em projetos, em uma experiência desenvolvida no ano de 2020 dentro de um projeto integrado aplicado em 21 turmas no IFMT/ Campus Primavera do Leste.

Dentro do proposto verificou-se o desenvolvimento das aulas baseadas em temas transversais propostos pelo projeto integrador, proporcionou aos alunos ações que possibilitou o protagonismo, promovendo a interação e a autonomia na aprendizagem que, de um modo geral, aos estudantes a percepção quanto a importância do projeto para o seu futuro profissional, por meio de experiências que propiciaram o desenvolvimento de suas competências transversais relacionadas ao trabalho em equipe, o gerenciamento de conflitos, a realização de tarefas em prazos determinados e a tomada de decisão para a concretização do projeto.

Por outro lado, foi possível observar que as características de um projeto integrador mudam o conceito de ensinar por ensinar, várias são as dificuldades que surgem quando se trata de modificar estruturas já consolidadas de qualquer natureza e esta realidade não é diferente na implementação de um novo método de ensino-aprendizagem.

No entanto, há ainda vários desafios a serem superados, tais como estimular o desdobramento das aulas do Projeto Integrador em novas atividades interdisciplinares e nas unidades curriculares. A segunda certeza é a de que os Projetos Integradores, se construídos nos moldes apresentados acima, são uma importante ferramenta para estimular a aprendizagem e a integração curricular e para a difusão de experiências educativas inovadoras e bem sucedidas.

\section{Referências}

ALVES, Lynn. Educação remota: entre a ilusão e a realidade. Interfaces Científicas, v. 8, n. 3 , p. $348-365,2020$.

ALVES, Lynn; MOREIRA, Antônio. (Orgs.) Tecnologias \& aprendizagens: delineando novos espaços de interação. Salvador: Edufba, 2017.

ANASTASI, Anne. Testes psicológicos. São Paulo: EPU/EDUSP; 1977. 


\begin{abstract}
ARAÚJO, Ulisses Ferreira de. Temas transversais, pedagogia de projetos e as mudanças na educação [recurso eletrônico]. São Paulo: Summus, 2014.
\end{abstract}

MARCONI, Marina de Andrade; LAKATOS, Eva Maria. Técnicas de pesquisa: planejamento e execução de pesquisas, amostragens e técnicas de pesquisa, elaboração, análise e interpretação de dados. $7^{a}$ edição. São Paulo, SP: Atlas, 2008.

MÉDICI, Mônica Strege; TATTO, Everson Rodrigo; LEÃO, Marcelo Franco. Percepções de estudantes do Ensino Médio das redes pública e privada sobre atividades remotas ofertadas em tempos de pandemia do coronavírus. Thema, v. 18, n. especial, p. 136 - 155, 2020 .

PAGANI, Geovane Santos. $\mathbf{N}^{\mathbf{0}}$ alunos matriculados ensino médio. Mensagem recebida por <fabiana.pomin@pdl.ifmt.edu.br> em 06 out 2020. Disponível em: https://mail.google.com/mail/u/0?ik=8dcaa29d4d\&view=pt\&search=all\&permmsgid=msg-

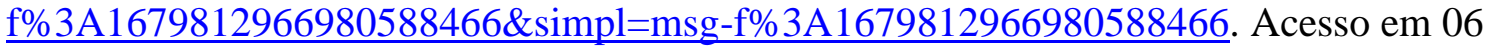
out 2020 .

POMIN, Fabiana. Ginástica. Curitiba: Intersaberes, 2020.

PRENSKY, Marc. Digital natives, digital immigrants part 1. On the horizon, v. 9, n. 5, p. 1-6, 2001. Disponível em: https://www.marcprensky.com/writing/Prensky\%20-

$\% 20$ Digital\%20Natives, \%20Digital\%20Immigrants\%20-\%20Part1.pdf. Acesso em 05 out. 2020.

RAMOS, Samira dos Santos et al. Projeto integrador Como não adiantar o fim do mundo. Plano de Ensino Interdisciplinar enviado ao Instituto Federal de Mato Grosso campus Primavera do Leste. Primavera do Leste: IFMT, 2020.

SILVA, Antônio Jansen Ferandes da; et al. A adesão dos alunos às atividades remotas durante a pandemia: realidades da Educação Física Escolar. Corpoconsciência, v. 24, n. 2, p. 57-70, 2020.

ZAJAC, Danilo. Educação remota na Educação Básica e COVID-19: um agravo ao direito à educação e outros impasses. Disponível em: < http://proec.ufabc.edu.br/epufabc/ensinoremoto-na-educacao-basica>. Acesso em 05 out. 2020. 